\title{
Non-denatured Soybean Extracts in Skin Care: Multiple Anti-Aging Effects
}

\author{
Miri Seiberg \\ The Johnson $\mathcal{E}$ Johnson Skin Research Center, CPPW, a division of Johnson $\mathcal{E}$ Johnson \\ Consumer Companies, Inc. Skillman, NJ, 08558,
}

USA

\section{Introduction}

Non-denatured soybean extracts contain all the ingredients of the soybean in their natural conformations, which is different from soy foods that must be denatured, or from soy isoflavone-based cosmetic products. The multiple benefits of non-denatured soybean extracts for skin care range from skin lightening, extracellular matrix enhancement and delayed hair growth, to a protective effect from photodamage and possibly from skin cancer.

The discovery of the role of the keratinocyte receptor Protease-Activated Receptor-2 (PAR-2) in keratinocyte-melanocyte interactions and pigment transfer resulted in the identification of novel agents that affect skin color. The inhibition of serine proteases was found to reduce PAR-2 activation and therefore to alter skin color. A search for naturally occurring serine protease inhibitors identified non-denatured soybean extracts. These extracts inhibit PAR-2 activation and induce human skin lightening. Non-denatured soybean extracts also enhance collagen and elastin synthesis, and protect existing elastin fibers from degradation, therefore providing anti-aging benefits such as reducing skin sagging and wrinkling. Additionally, non-denatured soybean extracts delay hair growth, resulting in thinner and smaller hair shafts and reduced visibility of undesired hair growth. Topical pretreatment with nondenatured soybean extracts reduces UV-induced edema and erythema, and additionally reduces UVB-induced DNA and cellular damage, which could lessen the risk of skin cancer. Thus non-denatured soybean extracts could serve as inexpensive, safe and efficacious natural agents, which provide multiple skin care benefits, ranging from protection to restoration.

\section{Non-denatured soybean extracts}

Denaturation, a process induced by external agents or stressors, leads to changes in the tertiary structure of proteins, resulting in the loss of their activity. Conventional soybean extracts used in the cosmetic and food industries are typically denatured. The cosmetic industry uses mainly organic extracts of soybeans, which are enriched with isoflavones (reviewed in Thornfeldt 2005). The organic solvent extraction process removes or inactivates most of the soybean proteins while concentrating the isoflavones. The food industry takes major steps to inactivate the soy proteins, particularly Soybean Trypsin 
Inhibitor (STI), which interferes with the process of food digestion. Industry standards include heating under pressure and alkaline soaking, which denature most of the soybean proteins (Liu, 1999). Interestingly, soybeans have been used in Asia for centuries as a dietary source of protein, and they have always been fermented to inactivate STI, thereby preventing the inhibition of trypsin activity which is needed for digestion of dietary proteins.

The non-denatured soybean extracts discussed in this chapter are different from soy foods and from cosmetic soy preparations in two major aspects. First, the non-denatured soybean extracts contain all the ingredients at the same proportions as in the native bean. No soybean constituent is removed or is specifically enriched during the processing of the beans, and all components of the beans remain in a "soy powder" preparation that serves as raw material. Second, the soy powder is kept in its natural, non-denatured state, with all the soybean proteins, and in particular STI, present and active. Non-denatured soybean extracts, therefore, cannot be used for dietary consumption, as they contain active STI (see e.g. Paine et al, 2001; Seiberg et al, 2001).

\section{The Soybean proteins STI and BBI are serine protease inhibitors}

The proteins STI, a Kunitz-type trypsin inhibitor, and BBI, the Bowman-Birk protease inhibitor (reviewed in (Birk, 1985; Kennedy, 1998), were first isolated from soybeans in the early 1940's. STI (reviewed in Birk, 1985) is a protein of 181 amino acid residues and a tertiary structure which is dependent on two disulfide bridges (reviewed in Song et al., 1998). BBI is an $8 \mathrm{kDa}$ protein with 81 amino acid residues and seven disulfide bonds that is a weak trypsin inhibitor and a strong chymotrypsin inhibitor (Billings et al., 1992). STI is heat labile (Song et al., 1998), while BBI has a stable conformation even after its disulfide bonds are broken by heating or treatment with acid and pepsin (Birk, 1985). STI and BBI are found only in the bean, and not in any other part of the soy plant (Birk, 1985). BBI is known for its chemo-preventive effects in different types of cancer (reviewed in Kennedy, 1998) and a soybean extract enriched in BBI has been under evaluation for chemo-prevention in clinical studies. STI and BBI have not been studied in the past for their topical effect on skin pigmentation, skin aging or skin cancer. This chapter summarizes the biological activities of STI, BBI, and non-denatured soybean extracts (containing STI and BBI), and describes molecular and cellular mechanisms affected by these agents, which lead to superior skin care and "anti-aging" benefits.

\section{Skin aging}

Skin aging is a complex phenomenon induced by endogenous (chronological) and exogenous (extrinsic) factors. Chronological aging is a genetically programmed, unavoidable process, while extrinsic influences (e.g., sunlight, wind, heat, cigarette smoke, or exposure to chemicals) could be at least partially controlled by the individual (reviewed in Uitto, 1986; Baumann, 2007; Uitto, 2008; Leyden,1990). Among the extrinsic factors, ultraviolet (UV) irradiation (sunlight, tanning beds) is the single most important cause of skin aging (reviewed in Uitto, 1986; Baumann, 2007; Uitto, 2008; Leyden, 1990). UV exposure leads to numerous changes in the skin, including epidermal and dermal thinning, a decline in collagen production and in the functionality of the dermal elastic network, and an uneven distribution of pigment deposition, all resulting in an aged-skin phenotype. Additionally, $\mathrm{UV}$ exposure is a major factor in the development of skin cancer. Most skin cancers are 
induced by the cumulative exposure to UV irradiation, and therefore appear mainly on aged skins (see e.g. Strom and Yamamura, 1997).

\section{Non-denatured soybean extracts reduce pigment production and deposition}

The irregular pigmentation displayed in photo-damaged skin includes numerous types of hyperpigmented lesions, commonly referred to as "age spots". These UV-induced lesions are the result of uneven distribution of pigment cells, local loss of melanocytes, hyperactivity of melanocytes, and modified keratinocyte-melanocyte interactions (reviewed in Ortonne 1990). Therapies for hyperpigmented lesions range from cryotherapy and energy-based devices (e.g. laser, pulsed light), to chemical peels, and to topical pharmaceutical depigmenting agents (e.g. hydroquinone, tretinoin, adapalene), (Ortonne 2006). However, many of these treatments are expensive, or are accompanied by undesired effects (reviewed in Jimbow and Jimbow, 1998). The consumer needs safe, efficacious and cost effective depigmenting agents, and additionally desires "natural" treatments, with the expectations of safety, effectiveness and mildness at reasonable cost.

Early searches for depigmenting agents used cultured melanocytes (pigment cells) and assayed for either inhibition of tyrosinase activity (the rate-limiting enzyme in pigment production) or for selective melanocyte cytotoxicity. To better represent the complexity of intact skin, we used keratinocyte-melanocyte co-cultures in our studies. The co-culture system enabled us to identify keratinocyte-melanocyte interactions that are involved in pigment transfer, and later to modulate these interactions in a way that could alter skin color (Seiberg et al., 2000a, 2000b). A keratinocyte receptor, PAR-2, was identified as a phagocytic receptor that regulates the keratinocyte ability to ingest melanosomes (Sharow et al, 2000). Since PAR-2 is activated by serine proteases like trypsin (reviewed in (Déry et al., $1998,1999)$ ), its activation is inhibited by serine protease inhibitors. The modulation of the PAR-2 pathway was indeed shown to affect skin color. Activators of PAR-2 induced a visible skin darkening, and the inhibition of PAR-2 activation by serine protease inhibitors led to visible skin lightening (Seiberg et al 2000a, 2000b).

A search for botanical agents with a serine protease-inhibitory activity had identified nondenatured soybean extracts, and using the keratinocyte-melanocyte co-culture system documented that these extracts reduce pigment deposition (Paine et al, 2001). Nondenatured soybean extracts were later shown to reduce pigment deposition in human skin and to decrease the pigmentary levels of human age spots (Hermanns et al, 2000, Wallo et al, 2007). Non-denatured soybeans extracts contain the active trypsin inhibitors STI and BBI. Therefore, these purified proteins were tested, in parallel with the complete non-denatured soybean extract, for their ability to modulate pigment production and distribution. Nondenatured soybean extracts, or STI or BBI alone, were found to inhibit PAR-2 activation, resulting in cytoskeletal and cell surface reorganization and reduced keratinocyte phagocytosis (Paine et al, 2001). The depigmenting activity of these agents, as well as their ability to prevent UV-induced pigmentation, was demonstrated both in vitro and in vivo (Paine et al, 2001). Importantly, the non-denatured soybean extracts were superior to either STI or BBI alone in their depigmenting effect, even though the concentrations of STI and BBI within these extracts were much lower than when tested individually (Paine et al, 2001). These studies suggest that the non-denatured soybean extracts contain additional active agents besides STI and BBI, which either contribute directly to the depigmenting effect, or 
enhance the delivery or the activity of STI and/or BBI in the skin. Examples of the depigmenting activity of non-denatured soybean extracts are shown in figure 1 (Images courtesy of Dr. C.B. Lin and D. Rossetti).

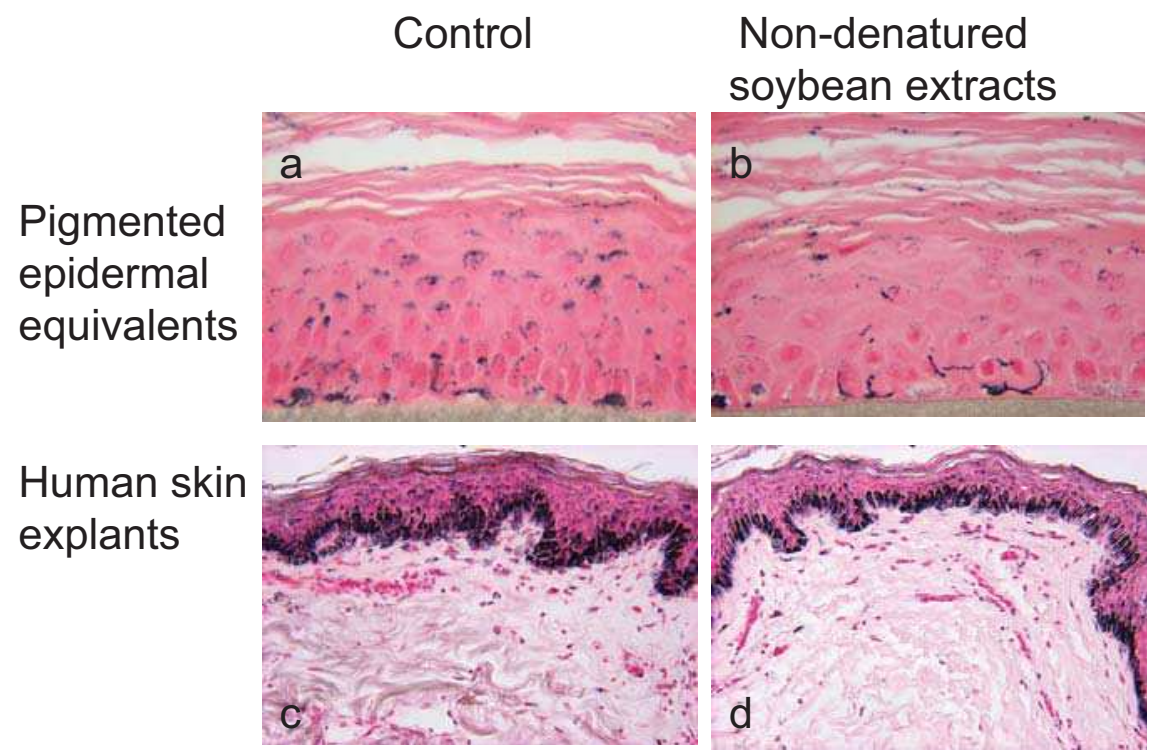

Fig. 1. Non-denatured soybean extracts reduce pigment production and deposition. (a-b)

Pigmented epidermal equivalents were topically treated with $2 \%$ non-denatured soybean extracts in PBS, or PBS alone, once daily, 5 days/week. Following nine days in culture the tissues were stained with Fontana-Masson (F\&M) staining, to document pigment deposition. A marked reduction was observed in the treated equivalents as compared to control. (c-d) Human skin explants were obtained from surgical procedures with informed consent and institutional board approval. Explants were maintained in culture for eight days, with or without topical daily treatment, 5 days/week, with a formulation containing $2.5 \%$ non-denatured soybean extract. F\&M staining documented a strong reduction in pigment production and deposition in the human skin following the non-denatured soy extract treatment. Images are courtesy of Dr. CB Lin and D. Rossetti.

\section{Non-denatured soybean extracts enhance the dermal extracellular matrix and the elastic fiber network}

Elastin fiber production is reduced with aging (reviewed in Uitto, 1986, 2008; PasqualiRonchetti and Baccarani-Contri, 1997). The age-induced decline in skin elasticity results from slower tissue regeneration, from lower elastin synthesis levels, and from the increased production and secretion of elastases. UV exposure further decreases the functionality of the elastic fiber network, as excessive elastin production and abnormal cross-linking create elastotic material ("solar elastosis") with reduced elastic capacity (reviewed in Uitto 1986, 2008). Preventing or reversing skin ageing includes the use of sunscreens and sun avoidance behavior, the use of anti-oxidants, and the use of agents like retinoids, which inhibit 
collagenases and promote collagen production (Baily et al, 1990; reviewed in Fisher and Voorhees, 1998). Only a few agents are available to directly enhance the balanced synthesis and assembly of the elastic fiber network. The inhibition of fibroblast-derived elastases following chronic UVB irradiation was found to protect the dermal elastic network of the skin from fragmentation, and to reduce wrinkle formation in rodents (Tsukahara et al, 2001a, b). Searching for botanical extracts for anti-aging skin care use, the non-denatured soybean

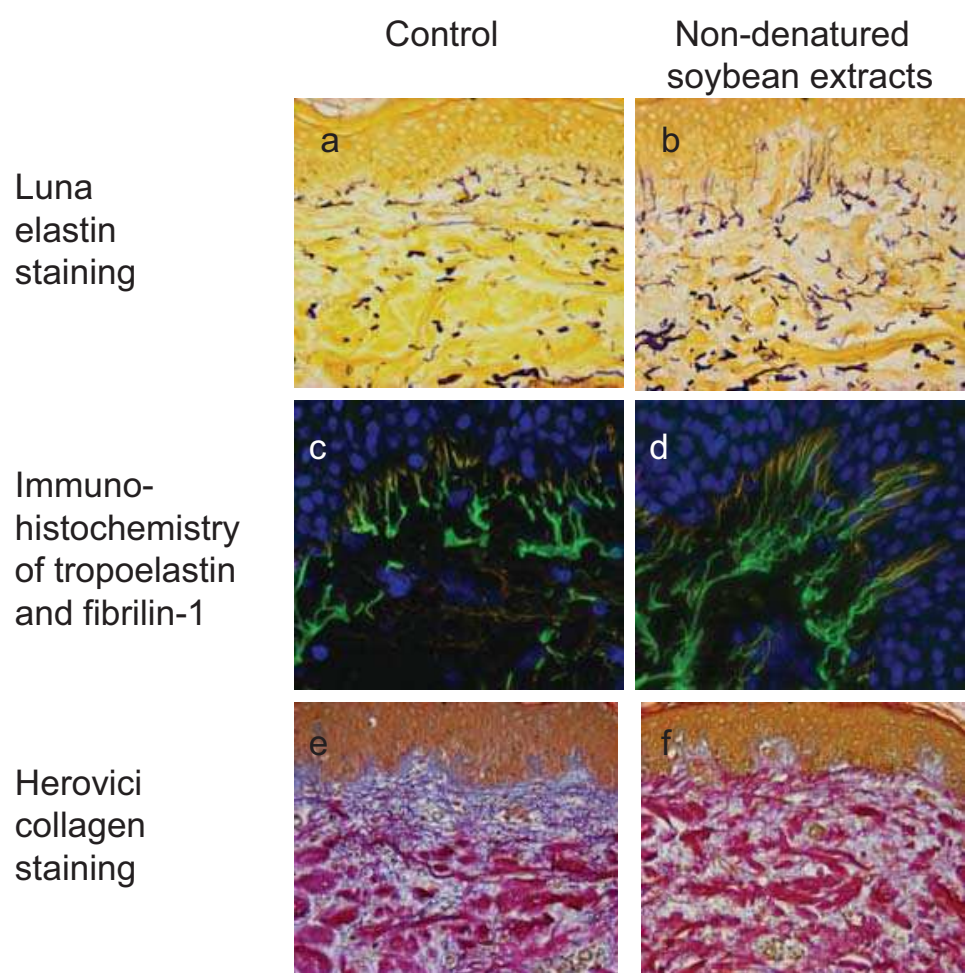

Fig. 2. Non-denatured soybean extracts enhance elastin and collagen synthesis. Human skin explants were obtained from surgical procedures with informed consent and institutional board approval. Explants were maintained in culture for eight days, with or without topical daily treatment, 5 days/week, with a formulation containing $2.5 \%$ nondenatured soybean extract. Histological and histochemical stainings were performed to document elastin and collagen fibers. $(a-b)$ Luna elastin staining. Mature elastin fibers are stained purple-brown. Topical treatment with non-denatured soybean extracts results in enhanced elastic fiber network. (c-d) Immuno-histochemical staining of tropoelastin (the elastin fiber monomer, green) and fibrillin-1 (an elastin-accessory protein, red). Colocalization is viewed as yellow. Non-denatured soybean extracts induce the synthesis of tropoelastin and fibrillin-1, and their co-localization documents the site of elastin fiber formation. (e-f) Herovici staining documents mature collagen fibers in magenta-red. Topical treatment with non-denatured soybean extracts induces the production of collagen fibers. Images are courtesy of Dr. CB Lin and D. Rossetti. 
extracts were found to have elastase-inhibitory activities (Zhao et al, 2009). In addition, nondenatured soybean extracts were found to induce the synthesis of collagen and elastin, and to promote the correct assembly of new elastin fibers, providing a complete protection and restoration to the dermal extracellular matrix (see Figure 2, images courtesy of Dr. C.B. Lin and D. Rossetti).

In vitro studies using both purified elastases and cultured fibroblasts demonstrated that non-denatured soybean extracts could affect the extracellular matrix. The enzymatic activity of several elastases was inhibited by these extracts, and, to a lesser extent, by STI or BBI, while soy isoflavones did not show any elastase-inhibitory activity (Zhao et al, 2009).. The non-denatured soybean extracts also protected elastic fibers produced by cultured fibroblasts from degradation by exogenously-added elastases (Zhao et al, 2009). Additionally, these extracts exhibited elastin-enhancement activities. A dose-dependent induction of expression of the elastin gene was documented using an elastin promoterluciferase reporter gene, and was confirmed by mRNA analysis of treated fibroblasts. The synthesis of new tropoelastin monomers, as well as of elastin-accessory proteins, and the assembly of new elastin fibers, was documented by histological staining (Zhao et al, 2009). The elastin-enhancing activity of the non-denatured soybean extracts was confirmed in vivo. Histological analysis of mice and swine skins topically treated with non-denatured soybean extracts showed a significant increase in the elastic fibers network, with an accompanied increase in elastin mRNA and in desmosine content (Zhao et al, 2009). When human skins, transplanted onto immuno-deficient mice, were topically treated with these extracts, an increase was documented in the expression of elastin, elastin-accessory proteins, and collagen (Zhao et al, 2009). Human skin explants treated ex-vivo with non-denatured soybean extracts and analyzed by histological staining and immunohistochemistry showed an increase in elastin, fibrilin-1 and collagen production (see Figure 2; Images courtesy of Dr. C.B. Lin and D. Rossetti). These data suggest that non-denatured soybean extracts not only protect extracellular matrix from degradation, they also induce collagen and elastin synthesis, and increase the total amount of stable, cross-linked elastin fibers.

\section{Non-denatured soybean extracts reduce hair growth}

Unlike other mammals, humans no longer use their hair for environmental protection, but keep or remove their hair for social and cosmetic purposes. Many procedures are used to remove unwanted hair, from simple home treatments like shaving, to laser and light therapies. These methods differ in the duration of hair elimination after removal, their price range, their pain and discomfort levels, and their possible undesired effects (reviewed in Olsen, 1999). Shaving, the most popular hair-removal method, requires daily treatments, may result in nicks and cuts, may increase the risk of infection, may leave a perception of an increased rate of hair growth, and may leave undesirable stubble. An alternative to at-home hair removal is hair dying or bleaching, used to reduce hair visibility in particular body areas. However, such methods are less preferred as the emerging portions of the hair shafts are always darker than the already-treated parts. An alternative to these methods is desired; particularly a method that would reduce undesired hair growth, with a safe and simple athome procedure. As the biological activities of the non-denatured soybean extracts were further explored, they were found to delay hair growth, resulting in smaller and thinner hair shafts (Seiberg et al, 2001). The use of a skin care product containing these extracts, therefore, would reduce the visibility of undesired hair growth. 
Topical daily treatments with STI or BBI visually delayed hair growth and reduced the length of the hair shafts of treated mice, with reduced hair follicles size observed histologically. Non-denatured soybean extracts (containing STI, BBI and isoflavones) were superior to either STI or BBI alone in this inhibitory activity. Non-denatured soybean extracts led to delayed and reduced hair growth, and hairs were visibly thinner, more "directionally organized", and smoother to touch, relative to untreated controls (Seiberg et al, 2001). Histological analysis confirmed these observations, and documented smaller size and less developed hair follicles (see Figure 3). A statistically significant effect on hair follicle dimensions was observed, with hair shaft diameter reduced by an average of $42 \%$, and hair bulb diameter reduced by an average of $23.8 \%$ (Seiberg et al, 2001). Additionally, the depigmenting effect of STI and BBI led to lighter colored hair shafts, which could potentially contribute to the reduced visibility of undesired hair growth. Heat-denatured soybean extract, or commercially available pasteurized soymilk, had no effect on hair growth or hair appearance (Seiberg et al, 2001), further supporting the involvement of intact STI and BBI in the hair growth inhibitory effect.

\section{Control}

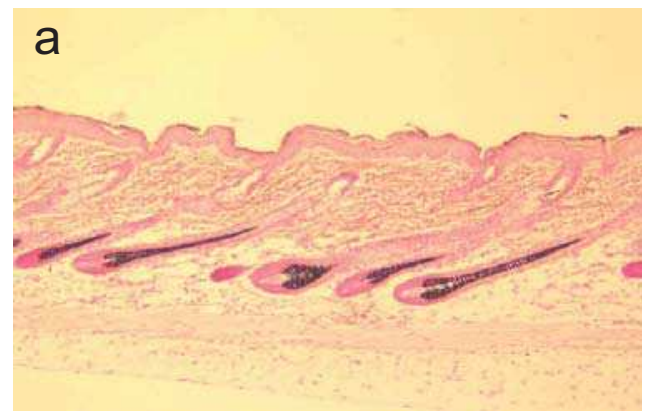

Non-denatured soybean extracts

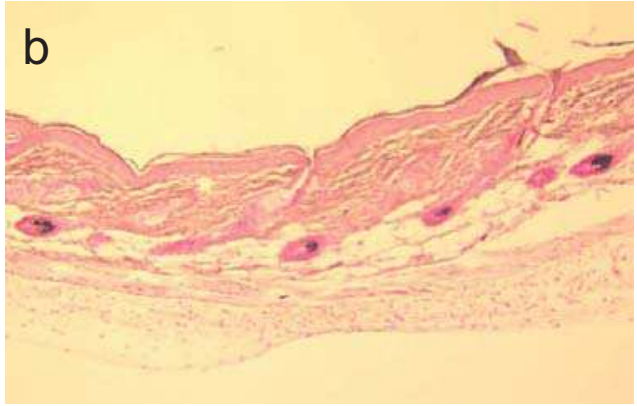

Fig. 3. Non-denatured soybean extracts delay hair growth. C57Bl/6 mice were wax depilated to induce a new hair cycle, and were treated daily with non-denatured soymilk (b) or remain untreated (a) as in (Seiberg et. al., 2001). F\&M staining of skin biopsies taken at day 7 of the hair cycle demonstrate delayed follicular development, and reduced hair follicle dimensions and pigment deposition in the soy-treated mice.

The non-denatured soybean extracts contain about $0.001 \%$ isoflavones. Phytoestrogens were shown to reduce hair growth in vitro (Hoffman et al, 1997), but to promote hair growth in mice and in volunteers with alopecia (Okajima and Harada, 2008). Therefore, the effect of the soybean-derived phytoestrogens on hair growth was studied, alone $(0.001 \%)$, and in combination with the whole non-denatured soybean extract (total $0.002 \%$ isoflavones). Isoflavones alone reduced mouse hair growth, but not as effectively as non-denatured soybean extracts alone. The combination of non-denatured soybean extracts, supplemented with $0.001 \%$ soybean-derived isoflavones, reduced hair growth to a higher degree than each preparation alone (Seiberg et al, 2001), suggesting complementary roles for STI, BBI and isoflavones in the hair growth inhibitory effect. These data suggest that non-denatured soybean extracts may serve as a natural alternative treatment for reducing the visibility of undesired grown hair.. 


\section{Non-denatured soybean extracts inhibit the COX-2 pathway, contributing to anti-aging and chemo-preventive effects}

Chronic inflammation has been linked to numerous skin diseases and conditions, including skin aging (Reviewed in Thornfeldt, 2008), and many skin care products, therefore, contain anti-inflammatory agents. Additionally, inflammation has been linked to epithelial skin tumors, and anti-inflammatory drugs are being studied for the prevention and treatment of non-melanoma skin cancers (Reviewed in Mueller, 2006). Cyclooxygenase-2 (COX-2), the main UV-responsive COX isoform in human skin, is involved in UV-induced skin inflammation and carcinogenesis (reviewed in Zhan and Zheng (2007); Rundhaug et al, 2007). UV-induced COX-2 expression plays a major role in UV-induced inflammation, edema, keratinocyte proliferation and epidermal hyperplasia, as well as in the generation of oxidative DNA damage. Repeated exposure to UV leads to chronic upregulation of COX-2 expression and chronic inflammation, contributing both to accelerated skin aging and to an increased risk of skin cancer. The induction of COX-2 expression by UV is higher in aged human skin as compared to young human skin, and aged human skin produces higher amounts of prostaglandin $\mathrm{E}_{2}\left(\mathrm{PGE}_{2}\right.$, the product of the COX-2 pathway ) relative to young skin (Seo et al, 2003). These data suggest that the aging of the skin may increase the susceptibility for developing both photoaging and carcinogenic processes. Oral and topical COX-2 inhibitors have chemopreventive activity against chemically- and UV-induced skin cancer in numerous animal models (reviewed in Zhan and Zheng (2007); Rundhaug et al, 2007). The topical applications of soy isoflavones to mouse skins before UVB exposure reduced the expression of COX-2 (Chiu et al, 2009).

Non-denatured soybean extracts were found to inhibit the COX-2 pathway both in vitro and in vivo (Chen et al, 2008). Cultured keratinocytes or epidermal equivalents were pretreated with non-denatured soybean extracts and then thoroughly washed prior to UV exposure. In the absence of treatment, UV irradiation induced COX-2 expression and $\mathrm{PGE}_{2}$ secretion, and induced the activation of p38 MAP kinase. Non-denatured soybean extracts reduced UVBinduced COX-2 expression and $\mathrm{PGE}_{2}$ secretion, and inhibited p38 MAP kinase activation in vitro (Chen et al, 2008). Mice pre-treated topically with non-denatured soybean extracts, then extensively washed prior to UV-exposure, had reduced levels of COX-2 expression in their skins at $24 \mathrm{hr}$ post UVB exposure, as compared to mice exposed to UVB alone, confirming the COX-2 inhibitory activity of the non-denatured soybean extracts in vivo (Chen et al, 2008). Examples of the COX-2 inhibitory activity of the non-denatured soybean extracts, and of the reduction in UV-induced $\mathrm{PGE}_{2}$ secretion are shown in Figure 4. The COX-2 inhibitory activity of the non-denatured soybean extracts suggests the possible delay of photoaging and skin cancer processes in human skin.

\section{Non-denatured soybean extracts reduce skin cancer progression in high- risk mice}

The photoprotective effects of polyphenols, including green tea polyphenols, resveratrol, and soy isoflavones like genistein, on UV-induced skin inflammation, oxidative stress and DNA damage, have been extensively documented (Reviewed in Nichols and Katiyar, 2010). Additionally, the chemopreventive effects of the soy protein BBI have been demonstrated, and an extract of soybeans enriched in BBI has been under evaluation in numerous human clinical studies for more than ten years (Kennedy, 1998). Oral feeding of mice with a non-denatured 

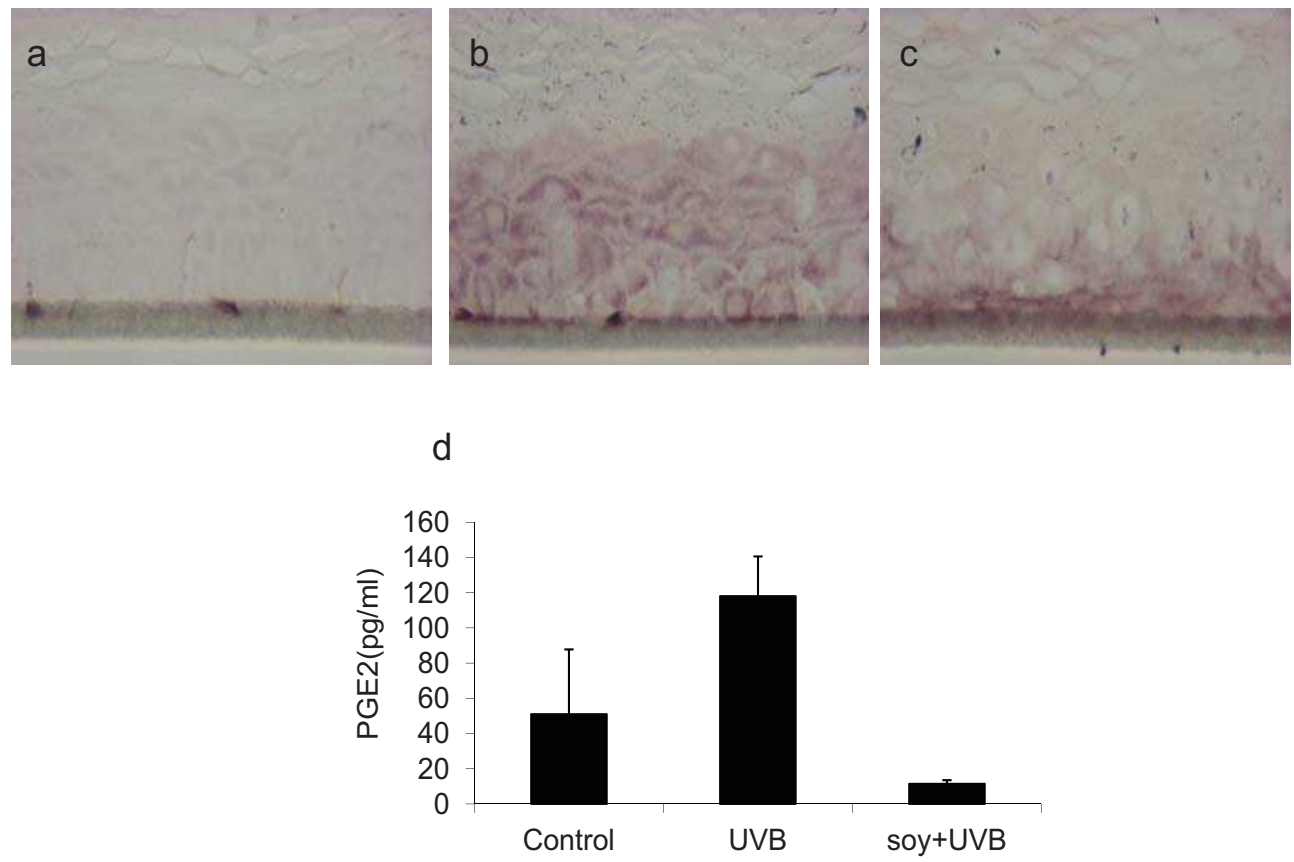

Fig. 4. Non-denatured soybean extracts inhibit the COX-2 pathway. Epidermal equivalents were treated with $2 \%$ non-denatured soybean extracts in PBS or with PBS alone for 24 hours, then washed extensively, followed by UVB exposure $\left(100 \mathrm{~mJ} / \mathrm{cm}^{2}\right)$ as in (Chen et al., 2008). Samples were collected at 24 hours post UVB exposure for COX-2 immuno-histochemical staining. (a) PBS. (b) PBS followed by UVB. (c) $2 \%$ non-denatured soybean extracts followed by UVB. COX-2 staining of the treated equivalents demonstrates the inhibitory effect of non-denatured soybean extracts on UVB-induced COX-2 protein levels. (d) Culture media were analyzed for $\mathrm{PGE}_{2}$ secretion. UV induced, and non-denatured soybean extracts inhibited the secretion of the inflammatory mediator $\mathrm{PGE}_{2}$.

soymilk protein supplement led to reductions in skin tumor numbers and volume when tumors were chemically induced (Limtrakul et al, 1993), however undesired gastrointestinal effects were observed during this study. Since non-denatured soybean extracts contain isoflavones and BBI, and since they possess COX-2 inhibitory activity, the use of these extracts as topical chemo-preventive agents was evaluated.

Hairless mice exposed for 20 weeks to chronic low levels of UV light become "high risk mice", which are tumor-free, but with a high risk of developing skin tumors during the next several months in the absence of additional UV exposure. The high-risk, UV-irradiated mice (with no visible skin lesions) were topically treated with non-denatured soybean extract, heat-denatured soybean extract, STI, or BBI, or with water or BSA as controls (Huang et al, 2004). Topical applications of non-denatured soybean extract but not of heat-denatured soybean extract to these high risk mice reduced the incidence and slowed the growth and progression of skin tumors (see Fig. 5a). Similar topical applications of STI or BBI also reduced the incidence, and slowed or inhibited the formation and growth of skin tumors, 
but to a lesser extent than the whole non-denatured soybean extract. The number of tumorbearing mice, the number of tumors per mouse, and the volume of the visible part of the tumors, were all reduced the most upon the topical treatment of non-denatured soybean extracts (Huang et al, 2004). Histopathological examination of skin sections from the untreated mice and from mice treated with heat-denatured soybean extracts all documented numerous squamous cell carcinoma (SCC) lesions. The non-denatured soybean extractstreated skins, in contrast, had only very small lesions, with no dysplasia or carcinoma (Figure 5b-d, images courtesy of C. Paine). These data might suggest that non-denatured soybean extracts could be topically applied to sun-exposed human skin to prevent sunlightinduced skin damage and to reduce the risk of skin tumor formation and progression.

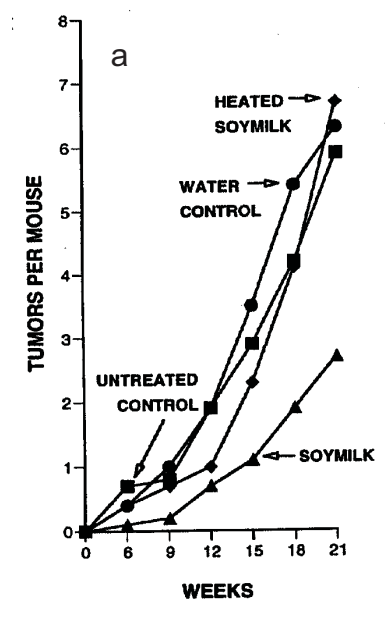

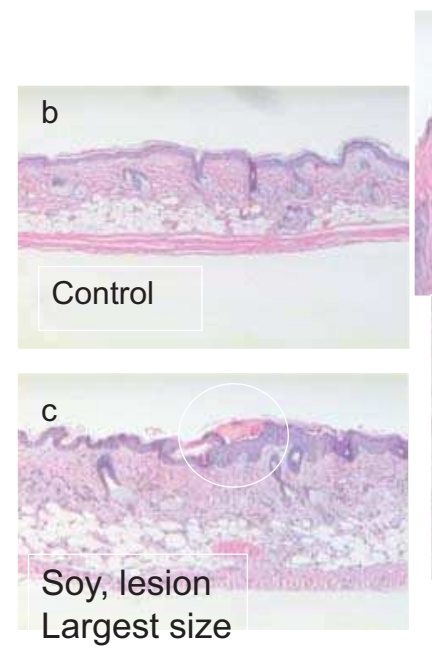

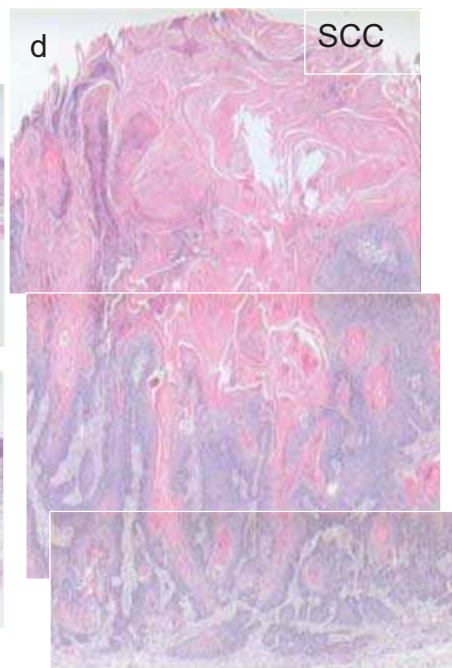

Untreated, tumor

Average size

Fig. 5. Non-denatured soybean extracts delay the progression of skin cancer in high-risk mice. SKH-1 mice were irradiated with UVB $\left(30 \mathrm{~mJ} / \mathrm{cm}^{2}\right)$ twice weekly for 20 weeks and UVB irradiation was then stopped, as in (Huang et al., 2004). Three weeks later, the mice were topically treated with non-denatured soybean extract ("soymilk"), heat-denatured soybean extract ("heated soymilk"), or water control, once a day, 5 days/week, for 21 weeks. (a) The number of visible tumors per mouse was determined every 3 weeks. Topical treatment with non-denatured soymilk, but not with heat-denatured soymilk, led to a marked reduction in the number of tumors per mouse. (b-d) H\&E staining of visible skin lesions and visually unaffected skins was performed at the end of the study. (b) Control skin (not exposed to UV and untreated). (c) Largest visible lesion of a non-denatured soymilktreated skin. (d) An average lesion in the high-risk, untreated group shows a welldifferentiated SCC. All images are of same magnification. Topical treatment with nondenatured soymilk significantly reduced the severity of the developing skin lesions. Images are courtesy of C. Paine. 


\section{Non-denatured soybean extracts reduce skin cancer risk by multiple mechanisms}

Non-denatured soybean extracts, as all botanical extracts, contain multiple agents, which are only partially characterized. It is expected, therefore, that such extracts would act by multiple mechanisms. Studies of the mechanisms of action of the chemopreventive activity of non-denatured soybean extracts identified effects both at the initiation and the progression of skin tumors, with multiple mechanisms affecting the tumor and the microenvironment (Chen et al, 2008). Topical pretreatment of hairless mice or Yucatan swine with non-denatured soybean extracts for several days prior to UVB exposure, prevented or reduced UVB-induced DNA damage (T-T dimers) and apoptosis. This reduction in the cumulative DNA damage in skin is, at least partially, mediated via the activation of the cell-cycle regulatory protein Chk1 (Chen et al, 2008). Non-denatured soybean extracts inhibit metallo-proteinases (MMPs) expression in vivo, suggesting the inhibition of dermal ECM remodeling, which is required for tumor progression. Vascular endothelial growth factor (VEGF)-induced endothelial tube formation in Matrigel was inhibited in vitro by non-denatured soybean extracts, suggesting a possible inhibitory effect on angiogenesis and tumor progression. Taken together with their ability to inhibit multiple proteases and to enhance ECM production (Zhao et al, 2009), their ability to inhibit the COX-2 pathway (Chen et al, 2008), and their content of intact STI and BBI, non-denatured soybean extracts could affect the tumor and the microenvironment at multiple stages of skin cancer initiation and development. Topical treatment with non-denatured soybean extracts, therefore, could reduce the risk of skin cancer development, by reducing UVB-induced DNA and cellular damage, and reducing microenvironment processes.

\section{Clinical studies with non-denatured soybean extracts}

An initial human clinical study using non-denatured soybean extracts for skin care was performed on hyperpigmentary lesions (Hermanns et al, 2000). Non-invasive image analysis was performed with high magnification pictures obtained with a UV-emitting unit and a sensitive fluorescence video recording, which could detect subclinical mottled skin pigmentation. Non-denatured soybean extracts led to significant skin lightening after a 3week treatment (Hermanns et al, 2000), suggesting, for the first time, that the inhibition of the PAR-2 pathway might present a novel approach for the treatment of pigmentary skin lesions.

The effect of non-denatured soybean extracts on hair growth was first evaluated in three Caucasian males with dark facial hair. Panelists treated one side of their face with the extracts, daily, immediately after shaving. By the forth week, the hair of the treated side was visually lighter and shorter, and felt smoother to touch. Image analysis of the treated areas four hours after shaving documented reduced length and thickness of the hair stubble at the treated side, with a statistical significant difference in all measured parameters (Seiberg et al, 2001). Examples of images from this study are shown in figure 6a-b. For the next proof of concept study, hair was wax-depilated of two symmetrical areas of the legs, below the knee, in two females, and one leg was treated daily, for four weeks, with nondenatured soybean extracts. Hair growth on the treated site was visually reduced, with the hair shafts visibly shorter and thinner than those of the control sites (Seiberg et al, 2001). 
Examples of images from this study are shown in Figure 6c-d. Later studies documented similar effects on women's facial hair. These observations confirmed the effect of nondenatured soybean extracts on delaying human hair growth, and suggested that this effect is not related to the method of hair removal or to the body part being treated.

\section{Control}
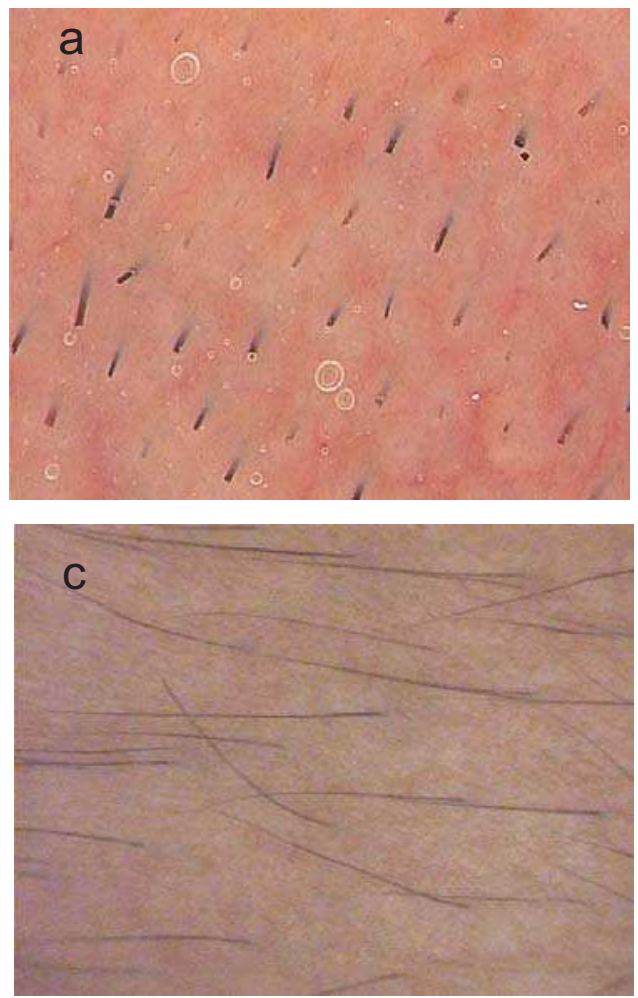

Non-denatured soybean extracts
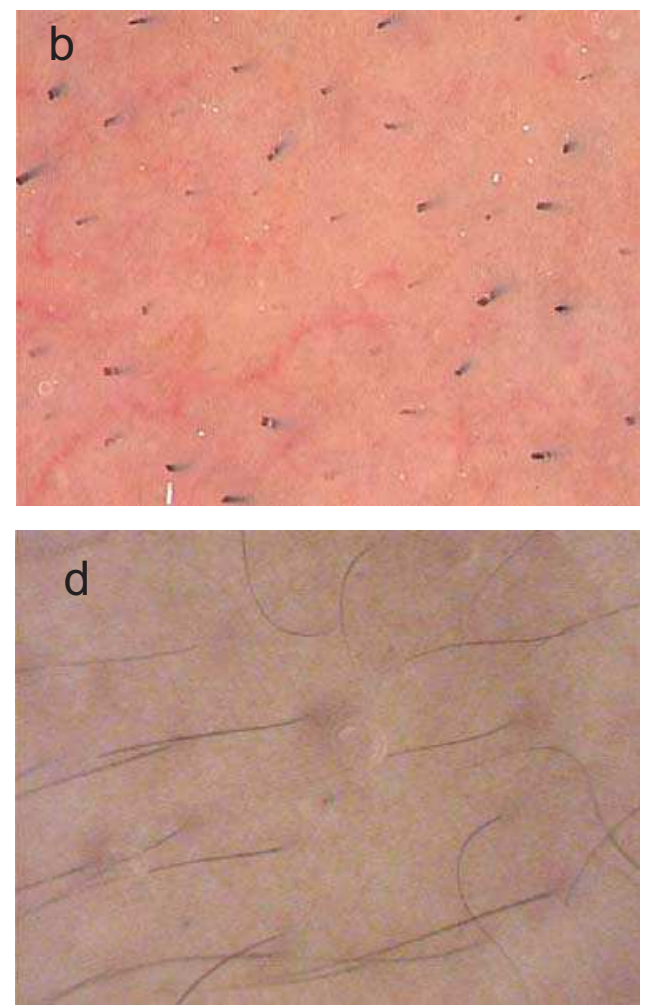

Fig. 6. Non-denatured soybean extracts reduce human hair length and thickness. (a-b) Caucasian males treated the right side of their face with non-denatured soybean extract, immediately after shaving. Digital pictures taken after four weeks of treatment, four hours after shaving, demonstrate reduced growth rate and dimensions of the hair stubble at the treated side (b), relative to the untreated control (a). (c-d) Hair was wax-depilated of two symmetrical areas of female legs, below the knee, and one leg was treated daily, for four weeks, with non-denatured soybean extract. Images taken at four weeks of treatment, six days after shaving, document reduced density and dimensions of the hair shafts at the treated side (d), relative to the untreated control (c).

The non-denatured soybean extracts were next evaluated in a placebo-controlled clinical study for their effect on UV-induced erythema, hyperpigmentation and peeling (Wu et al, 2001). Subjects were exposed to UV irradiation of about 1.5-2 MED, following by daily 
applications of the non-denatured soybean extract. Diffused reflectance spectroscopy measurements and independent dermatologist assessment concluded that UV-induced erythema was reduced at $24 \mathrm{hrs}$ after the application of non-denatured soybean extracts. At 7 days post irradiation, peeling was observed on some placebo or untreated sites, but not on the non-denatured soy-treated sites (Wu et al, 2001). This clinical, placebo-controlled study clearly demonstrates that non-denatured soybean preparations are beneficial for daily defense against solar irradiation. An example of the effect of pretreatment with nondenatured soybeans extracts on UV-induced erythema and peeling is shown in figure 7.

\section{Control}

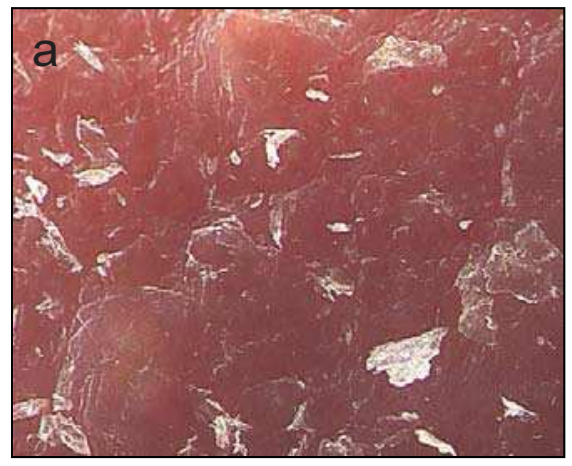

Non-denatured soybean extracts

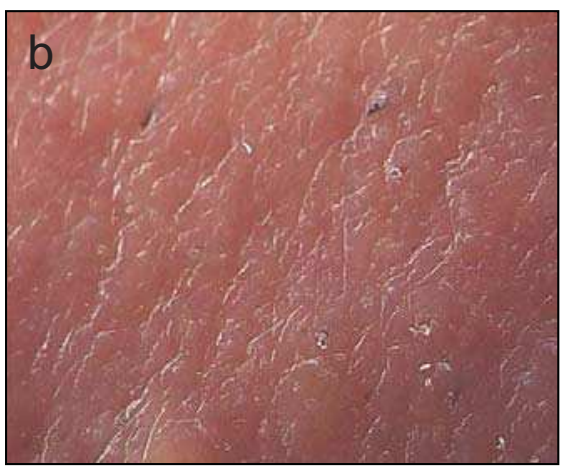

Fig. 7. Non-denatured soybean extracts reduce UV-induced erythema and peeling of human skin. A Caucasian male treated the right side of his face with non-denatured soybean extract, immediately after shaving, for six weeks, and was then exposed to solar irradiation during recreational activity. Digital Hi-Scope pictures taken 24 hrs post UV exposure, demonstrate reduced redness and peeling at the treated side (b), relative to the untreated control (a).

A double blind, placebo-controlled study of the efficacy of a moisturizer containing nondenatured soybean extracts was performed to evaluate the effects of this moistuizer on skin tone, skin pigmentation, and other photoaging-induced effects, in 63 women with moderate photo-damage (Wallo et al, 2007). Efficacy was monitored by clinical observations and selfassessments on weeks $0,2,4,8$, and 12, and by non-invasive measurements (such as colorimetric evaluations and digital photography) on weeks $0,4,8$, and 12 . The nondenatured soybean extract-containing moisturizer was well tolerated, and was more effective than the placebo in improving numerous photoaging parameters of skin color and texture, including overall skin tone, mottled pigmentation, blotchiness, dullness, fine lines, overall texture, and overall appearance (Wallo et al, 2007). Examples of the effect of the nondenatured soy extract moisturizer on skin pigmentation and on facial wrinkles are shown in 


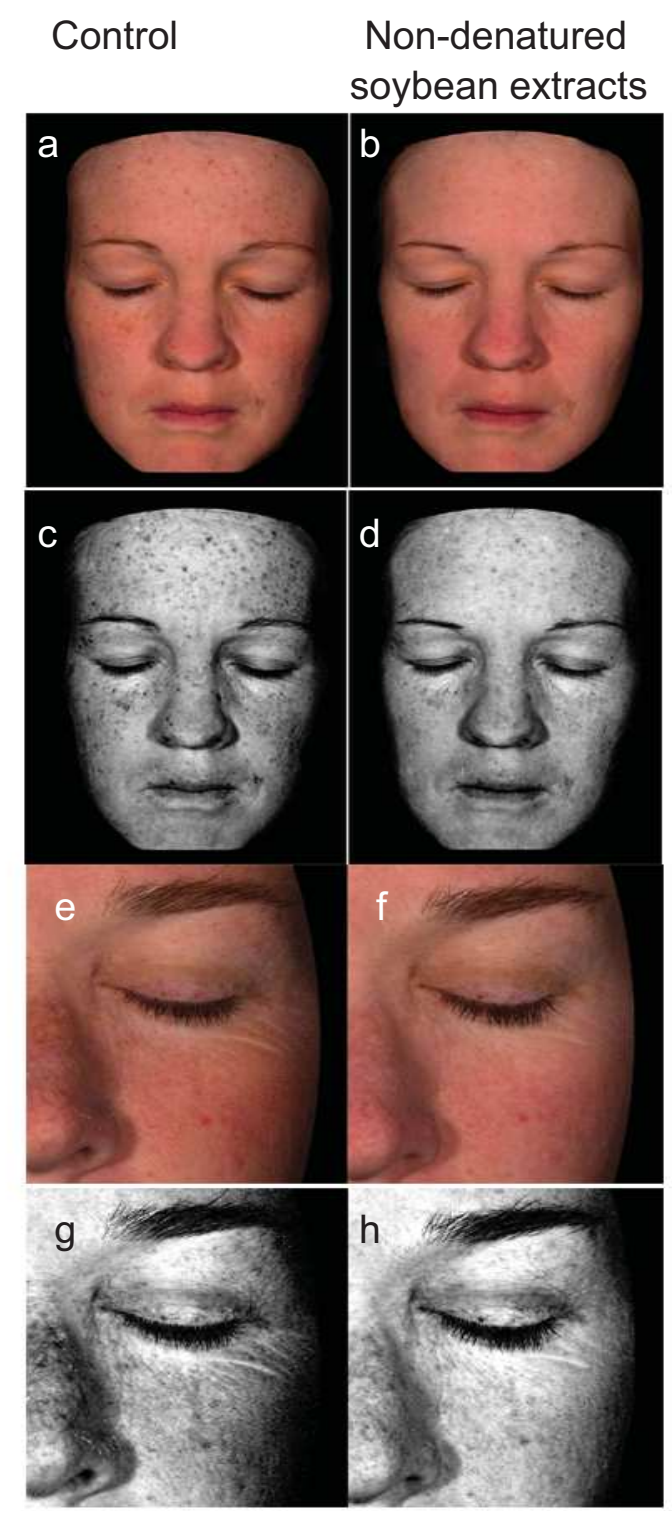

Fig. 8. Non-denatured soybean extracts reduce signs of photoaging. Women's faces were treated for 12 weeks, twice daily, with a moisturizer containing $2 \%$ non-denatured soybean extracts. A cross-polarized (a-b, e-f) and a black-and-white (blue-channel) of cross-polarized (c-d, g-h, enable visual enhancement of pigmentation changes) photographs were taken at baseline and at the end of the treatment period. (a-d) The images demonstrate improvement in skin tone, texture and radiance parameters following the treatment with non-denatured soybean extracts. (e-h) Images demonstrate improvement in wrinkling ("crow's feet") and in pigmentation parameters. Images are courtesy of $\mathrm{W}$. Wallo. 
figure 8 (Images courtesy of W. Wallo). The differences in photoaging parameters were significant from week 2 to week 12 for all above parameters (except for dullness, which started at week 4), suggesting that a moisturizer containing non-denatured soybean extracts is very effective in ameliorating photoaging-induced skin effects.

\section{Conclusion}

Preclinical and clinical studies, as well as mechanistic understanding, confirm that nondenatured soybean extracts, their formulations and their products, are safe and effective in improving numerous skin care parameters. Thus, the use of non-denatured soybean extracts provides multiple skin care benefits, ranging from protection and restoration, to aesthetic benefits.

\section{Acknowledgement}

The author would like to acknowledge the many individuals who had contributed to the studies of non-denatured soybean extracts over the years. Special thanks to Dr. C.B. Lin, D. Rossetti, C. Paine and W. Wallo for providing unpublished images for this publication. Many thanks to Drs. C.B. Lin and D. Cavender for critical reading of this chapter.

\section{References}

Bailly C, Drèze S, Asselineau D, Nusgens B, Lapière CM, Darmon M. (1990). Retinoic acid inhibits the production of collagenase by human epidermal keratinocytes. J Invest Dermatol. 94(1):47-51.

Baumann, L. (2007). Skin ageing and its treatment. J. Pathol. 211, 241-251.

Billings PC and Habres JM (1992). A growth-regulated protease activity that is inhibited by the anticarcinogenic Bowman-Birk protease inhibitor. Proc Natl Acad Sci 89: 31203124 .

Birk Y (1985). The Bowman-Birk inhibitor. Trypsin- and chymotrypsin-inhibitor from soybeans. Int J Pept Protein Res 25:113-131.

Chen N, Scarpa R, Zhang L, Seiberg M and C. B. Lin. (2008). Non-denatured Soy Extracts Reduce UVB-induced Skin Damage via Multiple Mechanisms Photochem Photobiol. 84:1551-9.

Chiu TM, Huang CC, Lin TJ, Fang JY, Wu NL, Hung CF. (2009). In vitro and in vivo antiphotoaging effects of an isoflavone extract from soybean cake. J Ethnopharmacol. 2009 Oct 29;126(1):108-13.

Déry O, Corvera CU, Steinhoff M, Bunnett NW (1998). Proteinase-activated Receptors: Novel Mechanisms of Signaling by Serine Proteases. Am. J. Physiol 247:C1429C1452.

Déry O and Bunnett NW (1999). Proteinase-activated Receptors: A Growing Family of Heptahelical Receptors for Thrombin, Trypsin and Tryptase. Biochem Soc Trans 27: 246254 . 
Fisher GJ, Voorhees JJ. (1998). Molecular mechanisms of photoaging and its prevention by retinoic acid: ultraviolet irradiation induces MAP kinase signal transduction cascades that induce Ap-1-regulated matrix metalloproteinases that degrade human skin in vivo. J Investig Dermatol Symp Proc. 3(1):61-8.

Hermanns JF, Petit L, Martalo O, Pierard-Franchimont C, Cauwenbergh G, Pierard GE (2000). Unraveling the patterns of subclinical pheomelanin-enriched facial hyperpigmentation: effect of depigmenting agents. Dermatology;201(2):118-22.

Hoffmann R, Eicheler W, Wenzel E, Happle R (1997). Interleukin-1beta-induced inhibition of hair growth in vitro is mediated by cyclic AMP. J Invest Dermatol 108: 4042.

Huang MT, Xie JG, Lin CB, Kizoulis M, Seiberg M, Shapiro S, and AH Conney (2004). Inhibitory Effect of Topical Applications of Non-denatured Soymilk on the Formation and Growth of UVB-induced Skin Tumors. Oncology Res. 14(7-8):387-397.

Jimbow and Jimbow (1998). Chemical, pharmacologic and physical agents causing hypomelanoses. P. 621-627. In: Nordlund, J. J., Boissy, R. E., Hearing, V. J., King, RA and Ortonne JP, eds. The Pigmentary System, Oxford University Press.

Kennedy,AR. (1998). The Bowman-Birk inhibitor from soybeans as an anticarcinogenic agent. Am. J. Clin. Nutr. 68: 1406S-1412S.

Leyden, JJ. (1990). Clinical features of ageing skin. Br. J. Dermatol. 122 Suppl 35, 1- 3

Limtrakul,P.; Suttajit,M.; Semura,R.; Shimada,K.; Yamamoto,S. (1993). Suppressive effect of soybean milk protein on experimentally induced skin tumor in mice. Life Sci. 53: 1591-1596.

Liu,K., (1999). Nonfermented oriental soyfoods In: soybeans, chemistry, technology and utilization Aspen Publication, Gaithersburg, Maryland. P. 137-165.

Mueller MM. (2006). Inflammation in epithelial skin tumours: old stories and new ideas. Eur J Cancer. 42(6):735-44.

Nichols JA and SK Katiyar (2010). Skin photoprotection by natural polyphenols: antiinflammatory, antioxidant and DNA repair mechanisms. Arch Dermatol Res. 302(2):7183.

Okajima K, Harada N. (2008). Promotion of insulin-like growth factor-I production by sensory neuron stimulation; molecular mechanism(s) and therapeutic implications. Curr Med Chem.;15(29):3095-112.

Olsen EA (1999). Methods of hair removal. J. Am. Acad. Dermatol. 40:143-55; quiz 156-7.

Ortonne JP. (1990). Pigmentary changes of the ageing skin. Br J Dermatol; 122 Suppl 35:21-8.

Ortonne, JP. (2006). Retinoid therapy of pigmentary disorders. Dermatol.Ther. 19, 280-288.

Paine C, Sharlow E, Liebel F, Eisinger M, Shapiro S and M Seiberg (2001). An alternative approach to depigmentation by Soybean extracts via inhibition of the PAR-2 pathway. J. Invest. Dermatol. 116(4): 587-595.

Pasquali-Ronchetti I, Baccarani-Contri M (1997). Elastic fiber during development and aging. Microsc.Res.Tech. 38:428-435.

Rundhaug JE, Mikulec C, Pavone A, Fischer SM. (2007). A role for cyclooxygenase-2 in ultraviolet light-induced skin carcinogenesis. Mol Carcinog. 46(8):692-8. 
Seiberg M, Paine C, Sharlow E, Andrade-Gordon P, Costanzo M, Eisinger M, Shapiro SS (2000a). The protease-activated receptor 2 regulates pigmentation via keratinocytemelanocyte interactions. Exp. Cell Res. 254:25-32.

Seiberg M, Paine C, Sharlow E, Andrade-Gordon P, Costanzo M, Eisinger M, Shapiro SS (2000b). Inhibition of melanosome transfer results in skin lightening. J Invest Dermatol.115:162-167.

Seiberg M, Liu JC, Babiarz L, Sharlow E and S. Shapiro (2001). Soymilk reduces hair growth and hair follicle dimensions. Exp. Dermatol. 10: 405-13.

Seo JY, Kim EK, Lee SH, Park KC, Kim KH, Eun HC, Chung JH. (2003). Enhanced expression of cylooxygenase-2 by UV in aged human skin in vivo. Mech Ageing Dev. 124(8-9):903-10.

Sharlow E, Paine C, Eisinger M, Shapiro S and M. Seiberg (2000). The ProteaseActivated Receptor-2 upregulates keratinocyte phagocytosis. J. Cell Sci. 113(pt 17): 30933101.

Song HK and Suh SW (1998). Kunitz-type Soybean Trypsin Inhibitor Revisited: Refined Structure of its Complex with Porcine Trypsin Reveals an Insight into the Interaction Between a Homologous Inhibitor from Erythrina caffra and Tissue-type Plasminogen Activator. J Mol Biol 275:347-363.

Strom SS, Yamamura Y. (1997). Epidemiology of nonmelanoma skin cancer. Clin Plast Surg. ;24(4):627-36.

Thornfeldt CR. (2005). Cosmeceuticals containing herbs: fact, fiction, and future. Dermatol Surg. 31(7 Pt 2):873-80.

Thornfeldt CR. (2008) Chronic inflammation is etiology of extrinsic aging. J Cosmet Dermatol. 2008 Mar;7(1):78-82.

Tsukahara K, Moriwaki S, Fujimura T, Takema Y (2001a): Inhibitory effect of an extract of Sanguisorba officinalis L. on ultraviolet-B-induced photodamage of rat skin. Biol.Pharm.Bull. 24:998-1003.

Tsukahara K, Takema Y, Moriwaki S, Tsuji N, Suzuki Y, Fujimura T, Imokawa G (2001b). Selective inhibition of skin fibroblast elastase elicits a concentration -dependent prevention of ultraviolet B-induced wrinkle formation. J.Invest Dermatol. 117:671-677.

Uitto, J. (1986). Connective tissue biochemistry of the aging dermis. Age-related alterations in collagen and elastin. Dermatol. Clin. 4, 433-446.

Uitto, J. (2008). The role of elastin and collagen in cutaneous aging: intrinsic aging versus photoexposure. J . Drugs Dermatol. 7, s12-s16.

Wallo W, Nebus J, Leyden JJ (2007). Efficacy of a soy moisturizer in photoaging: a double-blind, vehicle-controlled, 12-week study. J Drugs Dermatol.; 6(9):917-22.

J. Wu J, Stamatas G, Kollias N and JC Liu (2001). Soy for Daily Defense Against Sun Irradiation, International Proceedings on Skin and environment-Perception and Protection, $10^{\text {th }}$ EADV Congress, edited by J. Ring, S. Weidinger and U. Darsow.

Zhan H, Zheng H. (2007). The role of topical cyclo-oxygenase-2 inhibitors in skin cancer: treatment and prevention. Am J Clin Dermatol.8(4):195-200. 
Zhao, R, Bruning, E, Rossetti, D, Starcher, B, Seiberg, M, and Iotsova-Stone, V. (2009). Extracts from Glycine max (Soybean) induce elastin synthesis and inhibit elastase activity Exp Dermatol, 18(10):883-6. 


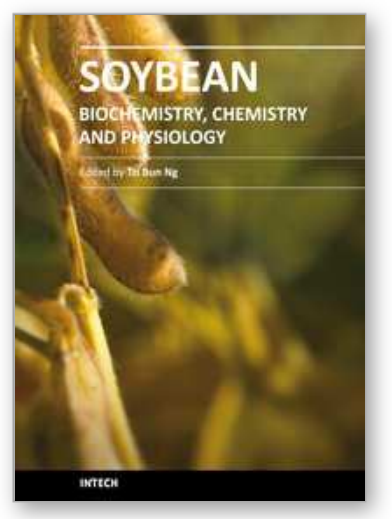

\section{Soybean - Biochemistry, Chemistry and Physiology \\ Edited by Prof. Tzi-Bun Ng}

ISBN 978-953-307-219-7

Hard cover, 642 pages

Publisher InTech

Published online 26, April, 2011

Published in print edition April, 2011

Soybean is an agricultural crop of tremendous economic importance. Soybean and food items derived from it form dietary components of numerous people, especially those living in the Orient. The health benefits of soybean have attracted the attention of nutritionists as well as common people.

\section{How to reference}

In order to correctly reference this scholarly work, feel free to copy and paste the following:

Miri Seiberg (2011). Non-denatured Soybean Extracts in Skin Care: Multiple Anti-Aging Effects, Soybean Biochemistry, Chemistry and Physiology, Prof. Tzi-Bun Ng (Ed.), ISBN: 978-953-307-219-7, InTech, Available from: http://www.intechopen.com/books/soybean-biochemistry-chemistry-and-physiology/non-denaturedsoybean-extracts-in-skin-care-multiple-anti-aging-effects

\section{INTECH}

open science | open minds

\section{InTech Europe}

University Campus STeP Ri

Slavka Krautzeka 83/A

51000 Rijeka, Croatia

Phone: +385 (51) 770447

Fax: +385 (51) 686166

www.intechopen.com

\section{InTech China}

Unit 405, Office Block, Hotel Equatorial Shanghai

No.65, Yan An Road (West), Shanghai, 200040, China

中国上海市延安西路65号上海国际贵都大饭店办公楼405单元

Phone: +86-21-62489820

Fax: $+86-21-62489821$ 
(C) 2011 The Author(s). Licensee IntechOpen. This chapter is distributed under the terms of the Creative Commons Attribution-NonCommercialShareAlike-3.0 License, which permits use, distribution and reproduction for non-commercial purposes, provided the original is properly cited and derivative works building on this content are distributed under the same license. 